\title{
METAMODEL OF A SERVICE-ORIENTED BUSINESS
}

\author{
Milosav Majstorović ${ }^{1}$, \\ Dušan Regodić2, \\ Gojko Grubor ${ }^{3}$
}

\author{
${ }^{1}$ Information Technology School, \\ Belgrade, Serbia \\ ${ }^{2}$ Singidunum University, \\ 32 Danijelova Street, Belgrade, Serbia \\ ${ }^{3}$ University of Sinergija, \\ Bijeljina, The Republic of Srpska, B\&H
}

\section{Correspondence:}

Milosav Majstorović

e-mail:

milosav.majstorovic@its.edu.rs

\begin{abstract}
:
In order to maintain their competitiveness or to achieve the desired position in the dynamic market environment, a vast majority of companies are turning to service-oriented business concepts. These changes require the design of a new business model that will take into account a new business approach. This task presents a great challenge for company managers, who are often burdened with the traditional view on business models. However, in order to facilitate this challenge, the appropriate approach and tools are required. The well-known approaches to development of service-oriented business provide informal and semi-formal tools that can produce ambiguities and which give limited possibilities for application of software tools in design. This paper presents service-oriented business as an ontological meta model aimed at solving the above mentioned problem. The developed meta model represents a unique conceptualization and it contributes to a more precise definition of service-oriented business concepts. The paper illustrates one possible application of the developed meta model for creating serviceoriented business model of a certain organisation (company) through meta model instance. This application is implemented in an insurance company, life insurance sector.
\end{abstract}

Key words:

service-oriented business, ontology, meta model, service-oriented business model, meta model instance.

\section{INTRODUCTION}

Service-oriented business provides services to its clients, i.e. customers. Generally, businesses and companies can be classified as those which provide goods (tangible items) and those which provide services. The companies that provide goods include mines, farms, factories, etc. Banks, retail facilities, communication media, health institutions, insurance companies, etc., are the examples of organizations with service-oriented businesses (SOB). Information services, including software companies and Internet-based organisations are becoming a significant part of the service-providing industry. Therefore, this business forms so-called Service Industry, i.e. service sector which represents the main sector of the economy of developed countries. In these countries, service sector acquires more than $70 \%$ of gross national product and employment rate for years (Stauss, 2008).

Current and upcoming radical business transformation and innovative logic in the domain of high technology industry (e.g. ICT and 
pharmaceutics) demand that the companies reconsider the approach to their main activities. For example, in addition to the focus orientation towards the development of new software products, ICT companies must find new business opportunities in the service sector. In service business, service is the basis of value creation. If they want to become competitive or to maintain their competitiveness, they have to change their focus from goods towards services. When doing this they have to change the entire business logic from production of both goods and services for clients, towards creation of new values together with their clients (Wallin, 2012). These changes require the design of a new business model which will support a new approach to business.

Due to the growing popularity of the Internet, the attention focused on business models significantly increased in the middle of the 1990s not only in industrial, but also in academic circles (Zott et al., 2010). This fact was a consequence of increased competition of similar products and services, which required their differentiation through different business models (Giesen et al., 2007). At the system level, the concept of business model offers a comprehensive view of the business logic and activities required for successful business operations, and it is particularly focused on the presentation of value creation (Zott et al., 2010).

Despite the application of business model concept in SOB, the existing approaches have their drawbacks in treating SOB characteristics (Zolnowski and Böhmann 2011). Also, the familiar approaches to the development of service-oriented business models (SOBM) provide informal and semi-formal tools that can produce ambiguities and offer limited possibilities for application of software tools in designing.

Aimed at solving the above mentioned problems, this paper presents $\mathrm{SOB}$ as an ontological meta model which takes into consideration the characteristics of Service Dominant Business Model (SDBM), and reflects the process of its creation (described in Luftenegger et al., 2013). The developed meta model contributes to a more precise definition of business model elements for $\mathrm{SOB}$, and creates an assumption for development of software tools which would provide easier creation of business models. The paper illustrates one of the possible applications of the developed meta model for creating SOBM of a specific organization (company), through meta model instance. This application has been carried out in the case of an insurance company (IC), life insurance sector.

Section 2 discusses the conceptual modelling, the concept of meta model and ontology from an academic perspective, and then elaborates on the concept of a busi- ness model. Special attention is paid to SDBM. The new ontology meta model of $\mathrm{SOB}$ that shows logical structure and semantics of $\mathrm{SOB}$ elements and their relationship is given in Section 3. Section 4 presents the development of SOBM in the organization of a specific field (the insurance industry) through ontological meta model instancing. Section 5 considers the achieved results and ideas for further work.

\section{RELATED PAPERS AND BASIC CONCEPTS}

\section{Conceptual Modelling, Meta models and Ontologies}

There is a widespread use of conceptual models which facilitate the development, implementation and maintenance of information systems (IS). Conceptual modelling is described as "a formal description activity" of the aspects of natural and social phenomena for the purpose of understanding and communication among people. One of the advantages of conceptual modelling application is the possibility to include semantics of the desired concepts by using formal notation. The result of conceptual modelling is the description intended for people and not for machines. Therefore, the semantics contained in conceptual models is in most cases implicit, and cannot be processed automated (Fill, 2009). This paper uses UML language to express the conceptual model of SOB, with the emphasis being places on the simplicity of the model component structure view. The conceptual model created in such a manner can be extended for the purpose of explicit modelling of implied semantics, thus making it suitable for processing by using the techniques indicated in (Fill, 2009).

Models as the abstraction of specific phenomena play a significant role in modern software engineering, and they can be found at various levels of abstraction. At the higher level of abstraction "a model of the models" is called meta model, i.e. the model is an instance of meta model (OMG, 2011). Compared with other approaches for modelling language description, such as grammar graph or logic formalisms, meta models offer an intuitive approach to semantics specification; therefore, they are suitable for non-technical customers. Meta models are particularly suitable for definition of conceptual models (Fill, 2009). They also are used for this purpose herein.

In (Atkinson, 2003) two orthogonal dimensions of meta modelling are separated: a linguistic and an ontological one. The difference between these dimensions is reflected in the form of meta model instancing. The linguistic dimension deals with the definition of language and the relation between its elements. The ontological 
dimension deals with identification and description of the elements within the observation domain. Therefore, ontological meta models are connected with classification of model elements, in accordance with their type, role and content. This paper uses ontological instancing in order to create a meta model of SOB and the derivation of business model of a service-oriented company by instancing the developed SOB meta model.

\section{Business models}

The interest in business models has become especially prominent since mid-90s, which resulted in more approaches for creating business model. The traditional concept of business model promotes dual focus: creation of value and assurance of value. Creation of value relates to the way that a company creates value for a customer. Value assurance is related to the way in which a company obtains benefit from the value creation process (Luftenegger et al., 2013).

In (Zott et al., 2011) the overview of literature related to business model is given, which covers many research fields and gives a comprehensive perspective. These research fields include: strategic approach to business models, e-commerce, innovations and technology management. Taking into consideration different development fields in business model research, Zott et al. (2011) identified the following aspects and catalysts for unique research of business models:

- First, business model itself is a concept focused on a particular company, but its scope extends beyond the boundaries of the specific organization.

- Second, at the system level business models refer to how the company realises its business.

- Third, management activities are crucial in the proposed conceptualization of a business model.

- Fourth, a business model aims to explain creation and assurance of value.

Business model concept has multiple definitions, which can lead to confusion and slower improvement in research and development of business models. One way to overcome this issue is development of ontology for business domains. Ontology can enable better definition and understanding of a particular business model and give a basis for the use of software tools as support to creating business models (Osterwalder, 2004). Some of the best established ontologies of business models are REA (Resource Events Agents), $\mathrm{e}^{3}$ value, Business Model Ontology - BMO (Hauksson, 2013). Osterwalder
\& Pigneur (2010) gave a pattern for building a business model in the form of Business Model Canvas (BMC), which divides a business model into nine constitutional blocks. Each of these nine blocks can be grouped into four fields: offer, customer, infrastructure and finance.

\section{Service dominant business model}

Since the existing approaches to business model tools are limited by orientation towards tangible products as a dominant direction in business realization, in (Luftenegger et al., 2013) considerable effort was made towards conceptualization and development of tools for the design and analysis of business models for service dominant business. The context for this research was an interdisciplinary vision of Service Science.

Luftenegger et al. (2013) distinguish the concept of value in Service Science from a traditional view on the value in business models. Namely, value creation in the literature on business models is usually connected with production processes, where a company creates values (in commercial sense) when a product is sold to a customer. In this traditional view, when the value is created as a product (e.g. a car) it can be added through service (e.g. car maintenance). In this approach, the value is distributed as a product, and the service becomes a postproduction process, where value can be added to the value based on product. However, Service Science treats final values through collaboration with the customer (joint creation of value). In this respect, the value is created through utilization, i.e. through benefits that are gained by using the product. Thus, Luftenegger et al. (2013) use the concept "value in use" in conceptualizing a business model within the Service Science.

Following the Service Dominant Strategy (SDS), Luftenegger et al. (2012a, 2012b) took into consideration the specific business aspects such as competences and collaboration values, relationships initiated from the inside, relationships initiated from the outside of an organization, as well as the role of participants and infrastructure resources. The Strategy is taken as a factor that has an impact on designing business models. Therefore, the specific business models with service oriented business are designed by using service dominant logic (Vargo and Lusch 2004) and (Vargo and Akaka 2009).

Luftenegger et al. (2013) use BMC derived from business model ontology (Osterwalder, 2004), in building the ontology of Service Dominant Business Model (SDBM). In doing so, they started from SDS as a basis (Luftenegger et al. 2012a). Starting from the statements related to 
SDS, its elements were obtained through answers to the following questions:

1. How is the company connected with business environment in service dominant business?

2. How does the company realize business relations in service dominant business?

3. Which constitutional elements does the company require to realise service dominant business?

The answers to the above questions identify the elements which are grouped into the following categories: market relations, business competences and business resources. The elements of SDS are also presented in (Luftenegger et al., 2012a) through so-called canvas of SDBM (similar to the business model (Osterwalder and Pigneur, 2010)). The elements of SDS obtained in this way are used as a baseline for gaining elements of SDBM. Luftenegger (2014) gives the procedure for obtaining these elements, which has been used for creating ontological meta model of $\mathrm{SOB}$ in this paper.

\section{META MODEL OF SERVICE-ORIENTED BUSINESS}

Figure 1 shows meta model of SOB. It is created on the basis of BMO (Osterwalder, 2004), BMC (Osterwalder and Pigneur, 2010), SDBM (Luftenegger, 2014) and the authors' experience. The meta model shows elements of SOB and their relationships. The following text briefly describes the elements of meta models and their relationships.

The concept of value often has multiple interpretations in literature. One of the meanings is usefulness, i.e. the significance of a business service or product. Vargo and Lusch (2004) suggest that the value is not an internal characteristic of a service, i.e. product, but it is established by the customer of the product, i.e. service as a utilization value, while the company only creates "value proposition". Having this in mind, in meta model these aspects of value concept are divided into three classes: Mutual Value Proposition, Value in Use and Product/Service.

Unlike the traditional concept of value proposition in BMC, Figure 1 emphasises that the value is created through the element of Mutual value proposition by interaction and participation of several participants, i.e. the suggested value should represent the solution to a certain issue of the customer. During the process of utilization, the value proposition becomes "utilization value" (the class value in use). Utilization value is reached through product or service usage (the class Product/Service)
The class Participant is an abstract class that designates all types of participants that appear in business. This superclass is suitable for modelling characteristics and relationships that all the participants in business have. Thus, all the participants in business realisation perform specific activities (the class Activities). The partnership, i.e. relations between participants, is enabled through the activities of the participants (the class Partnership). Partnership is a sort of agreement between participants (the class Partnership is a subclass of the class Agreement). Partnership itself can represent several agreements (the relation Set of between the classes Partnership and Agreement).

The intention to create value proposition in SOB through mutual activity of participants in the process has been illustrated by the relation Based on between the classes Mutual Value proposition and Partnership. Likewise, the product i.e. service is created through the partnership between the participants. The key role of partnership in $\mathrm{SOB}$ is also emphasized by the relation Assures towards the class Benefit. Therefore, the participants gain benefits through the partnership, which is also a motivation for their participation in the entire ecosystem.

Some specific resources are required in order to realise a business goal. The class Resource represents the concept which participates, i.e. which is used in the process of value creation. At the highest level of abstraction, the resources are instances of the class Participant, i.e. its subclasses Customer, Partner and Organisation (i.e. a company in the focus of a project). More specifically, the resources are composed of ICT infrastructure, employees, materials and other participants' capacities. The created value is delivered through a specific distribution channel (the instances of the class Distribution channel) which belongs to one of the participants. The distribution channel participates in the total business costs.

The Capability class designates the concept that is an abstraction of system elements which represent its behaviour. More specifically, capability is the ability of an entity (department, organisation, person, system, etc.) to perform activities which contribute to the accomplishment of its tasks especially within the mission of the whole system. In our approach, capability is also a type of resource (a subclass of the Resource class). A specific resource is provided by a respective participant, and capability enables the participant to contribute to value creation. Through their activities all the participants make specific costs (the appearance of the Cost class). The difference between gained benefits and operating costs is a realised profit. Therefore, profit is thus a derived element, so it is not specifically presented at the 


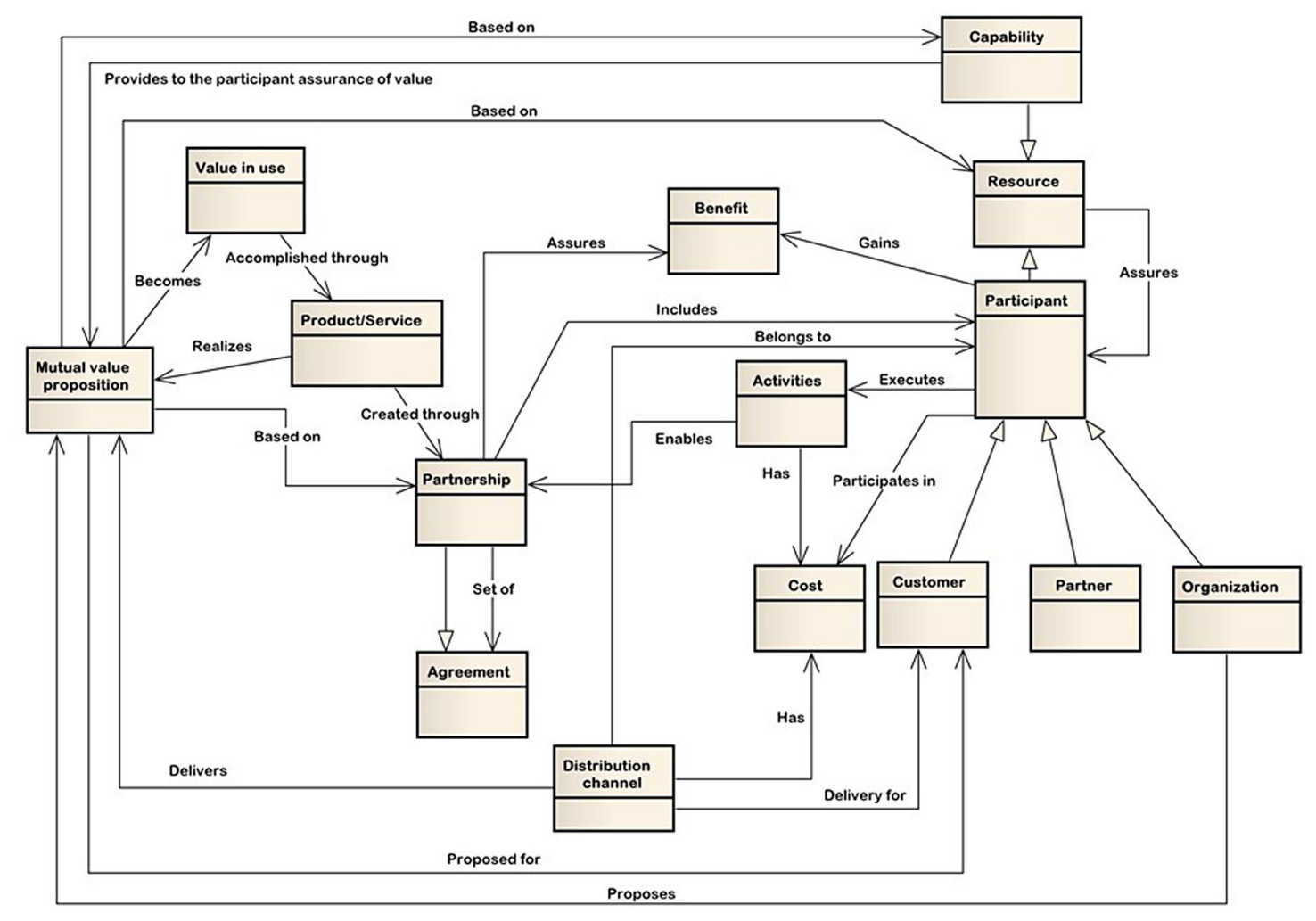

Figure 1. Ontological meta model of service-oriented business

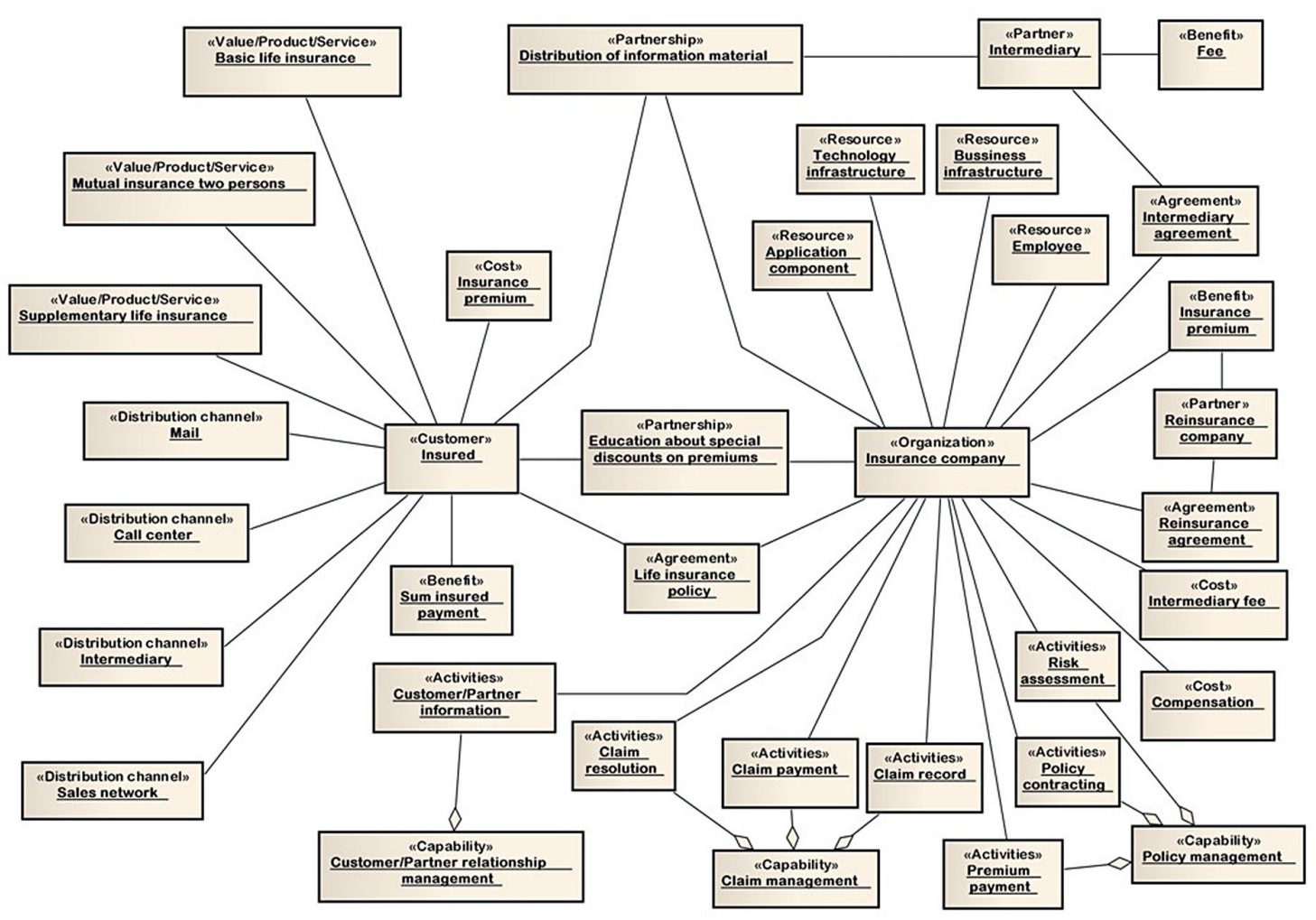

Figure 2.The example of SOBM of an organization 
meta model although it is certainly one of the business objectives (except in non-profit organisations). Due to the aspiration towards simplicity and transparency of the meta model diagram, it does not show all the relations that exist between $\mathrm{SOB}$ concepts presented by the classes.

\section{SOBM OF AN ORGANISATION}

In our approach, the SOBM of a standardised organisation (company) from the specific domain, i.e. industry, is created by instancing the SOB meta model shown above, using SDBM (Luftenegger, 2014) and domain frameworks and standards. A business model from the domain of insurance industry will be presented here. Polaine et al. (2013) give theoretical and practical bases for service designing; they particularly deal with the insurance industry showing that insurance is a service, not a traditional product, which means that the insurance industry is characterized by SOB.

\section{SOB meta model instancing}

Figure 2 shows a SOBM for the insurance industry, life insurance sector. The model represents an instance of SOB meta model (Figure 1) shown with the UML object diagram. The objects presented in the diagram represent the instances of classes from the meta model. During the meta model instancing, the classes Mutual Value Proposition, Value in Use and Product/Service are presented by the object with stereotype $<<$ Value/Product/Service $>>$. The relationships between objects are not labelled, and as a principle, they inherit their semantics from the relations between the classes from the meta model. Also, for transparency purposes, the diagram does not show all the relationships. The objects are standardised, and they mostly designate the roles typical for a specific domain (in this case the insurance industry).

In the diagram that illustrates SOBM for life insurance sector (Figure 2), each object is assigned a stereotype marking a class of meta model whose instance it represents. During the instancing of meta model, ontology (Osterwalder, 2004) and BMC (Osterwalder \& Pigneur, 2010) are used, particularly a SDBM (Luftenegger, 2014). The domain frameworks and standards are used to include the semantics of a specific domain. In this case, ACORD Framework has been used - the framework which enables architectural basis for IC for faster and easier preparation and implementation of changes required for successful business in the dynamic market (Gregory, 2005).
Practically, SOB meta model instancing is realised by instantiation of its classes, starting from the basic premises of SOB (Wallin, 2012) and the answers to SDS questions, as well as BMC (Luftenegger et al., 2013) adjusted to the specific business domain. The examples of the particular $\mathrm{SOB}$ meta model classes instancing for the field of life insurance are given below. Instancing is done by the specification of SDS and BMC elements, using the domain knowledge given through the domain framework and standards. Thereby, the instantiation of objects is performed by addressing (confronting) SOB meta model elements with the questions what, who, how and how much.

What is Value Proposition and Value in Use for an IC? How can the IC enable Value in Use? The IC should create such a product, i.e. life insurance service, which will enable clients to acquire the desired basic and supplementary insurance by paying insurance premiums. When answering these questions we get the examples of objects which are class instances: Mutual Value Proposition, Value in Use and Product/Service.

How can IC achieve mutual business risk with its clients and partners in the context of the proposed values, i.e. life insurance service? By the selection of a particular insurance service and an appropriate insurance risk assessment for the specific client. The examples of objects which present answers to these questions are: Policy Contracting and Risk Assessment. Both objects are instances of the meta model Activities class.

How can IC accomplish cooperation with its clients and partners for the purpose of mutual value creation? Arranging meetings where customers could present their desires and capabilities; organising educational meetings where the possible special discounts on premiums would be presented; distributing info materials; meeting partners (banks, statistics institutes, agents, etc.) to share experience and encourage business cooperation. The examples of objects which represent answers to this question are: Education about Special Discounts on Premiums and Distribution of Information Material. Both objects are instances of the meta model partnership class.

Who are IC clients? The examples of IC clients in the life insurance are physical entities interested in life insurance (the Insured), persons interested in contracting insurance for themselves or for others (Policy Holder), persons on whose behalf the insurance is negotiated (Insurance Beneficiary). Figure 2 shows only the Insured object which is an instance of the meta model customer class.

What benefit will participants in a business network gain? The insured person gains benefit through the payment of insured amount (object: Sum insured payment), 
intermediary through the gained commission (object: Fee), IC and reinsurance company through received insurance premiums (object: Insurance premium). All objects are instances of meta model benefit class.

By answering all the SDS questions the elements of SOB model are obtained. The respective stereotype is granted to the model elements in accordance with the SOB meta model. By analysing BMC (Osterwalder \& Pigneur, 2010), it is verified that if all the fields are filled in taking into consideration the domain knowledge of the specific industry (in our case it is the life insurance industry). Finally, it is checked if each class from a meta model has obtained the respective instance. For the classes which are not instanced in the described procedure, the additional analysis is performed to complete their instancing. The analysis assumes certain repetition of the previous procedure. After creating the instances, their connection is performed in accordance with semantics of the SOB meta model.

\section{CONCLUSION AND FUTURE WORKS}

The growing importance of $\mathrm{SOB}$ in modern economy requires changes of business models in the companies which that want to apply SOB concepts. This has led to the question of adequate presentation of $\mathrm{SOB}$ concept in business models and definition of new approaches for their development. This paper has used meta modelling as an approach for SOB conceptualization. The ontological meta model is developed which represents the concepts of SOB. The meta model can represent a basis for the development of new business models in various domains of service business. The paper presents the creation of SOBM in an insurance company for the sector of life insurance, via instancing an ontological meta model.

Comparing to other existing approaches, the key benefit of our approach is the presentation of SDBM concepts through the ontological meta model which contributes to their more precise definition. Meta model reflects the process of SDBM creation, which begins from SDS and leads systematically to the identification of SDBM elements and their relationships.

In the future work, the semantic extension of the defined conceptual model (meta model) is planned, which would be suitable for machine processing. It would be used for the development of application which would provide software support for designing SOBM. Also, the research on synthesis of methodological framework for the development of SOB enterprise architecture is in progress, which would use the meta model presented in this paper. Therefore, the development of enterprise architec- ture would be in compliance with the defined business model, and the analysis of business model would show how the architectural changes affect business operations.

\section{REFERENCES}

Atkinson, C., \& Kuhne T. (2003). Model-Driven Development: A Metamodeling Foundation. IEEE Software, 20(5), 36-41. DOI: 10.1109/MS.2003.1231149.

Fill, H. G., \& Burzynski, P. (2009) Integrating Ontology Models and Conceptual Models using a Meta Modeling Approach (2009). In 11th International Protégé Conference, 23-26 June 2009. Amsterdam: Stanford Medical Informatics.

Giesen, E., Berman, S.J., Bell, R., \& Blitz, A. (2007). Three ways to successfully innovate your business model. Strategy \& Leadership. 35(6), 27-33. DOI: 10.1108/10878570710833732

Gregory A. M. (2005). THE BUSINESS INFORMATION REVOLUTION: Making the Case for ACORD Standards. New York: ACORD Corporation.

Hauksson H. (2013). Metamodeling for Business Model Design. Ms Thesis. Stockholm: Stockholm University, Department of Computer and Systems Sciences.

Luftenegger, E., Grefen, G., \& Weisleder, C. (2012a). The service dominant strategy canvas: Defining and visualizing a service dominant strategy through the traditional strategic lens. Eindhoven, The Netherlands: Eindhoven University of Technology.

Luftenegger, E., Grefen, G., \& Weisleder, C. (2012b). The service dominant strategy canvas: Towards networked business models. In 13th IFIP Working Conference on Virtual Enterprises, 1-3 October 2012. Bournemouth, UK: Springer.

Luftenegger, E. et al. (2013). The Service Dominant Business Model: A Service Focused Conceptualization. Eindhoven, The Netherlands: Eindhoven University of Technology.

Luftenegger, E. (2014). Service-Dominant Business Design. $\mathrm{PhD}$. Thesis. Eindhoven, The Netherlands: Technische Universiteit Eindhoven.

OMG. (2011). OMG Unified Modeling Language (OMG UML) Superstructure, Version 2.4.1. Retrieved November 11, 2015, from http://www.omg.org/spec/ $\mathrm{UML} / 2.4 .1 /$ Superstructure/PDF.

Osterwalder, A. (2004). The Business Model Ontology: a proposition in a design science approach, $\mathrm{PhD}$. Thesis. France: University of Lausanne.

Osterwalder, A. \& Pigneur, Y. (2010). Business Model Generation: A Handbook for Visionaries, Game Changers, and Challengers - preview. Retrieved November 15, 2015, from http://www.businessmodelgeneration.com. 
Polaine, A. Løvlie, L. \& Reason, B. (2013) Service Design From Insight to Implementaton, Brooklyn, New York: Rosenfeld Media, LLC.

Stauss, B., Engelmann, K., Kremer, A. \& Luhn, A. (2008). Services science: Fundamentals, challenges and future developments, Berlin: Springer.

Wallin, A,. Tähtinen J., \& Nuutinen M. (2012). Paths towards pioneering in service business. Kuopio, Finland: VTT Technical Research Centre of Finland.

Vargo, S.L. \& Lusch, R.F. (2004) Evolving to a new dominant logic for marketing. Journal of Marketing, 68(1), 1-17. DOI: 10.1509/jmkg.68.1.1.24036.

Vargo, S.L. \& Akaka, M.A. (2009) Service-dominant logic as a foundation for service science: Clarifications. Service Science, 1(1), 32-41. DOI: 10.1287/serv.1.1.32.
Zolnowski, A. \& Böhmann, T. (2011) Business modelling for services - Current state and research perspectives. In Proceedings of the Seventeenth Americas Conference on Information Systems, 4-7 August 2011. Detroit, Michigan.

Zott, C., Amit, R., and Massa, L. (June, 2010) The Business Model: Theoretical Roots, Recent Development, and Future Research. Retrieved November 01, 2015, from http://www.iese.edu/research/pdfs/ DI-0862-E.pdf.

Zott C., Amit R., \& Massa L. (2011). The business model: Recent developments and future research. Journal of Management, 20(5), 1019-1042. DOI: 10.1177/0149206311406265. 